\title{
THE EFFECT OF PREEMPTIVE GABAPENTIN ON POSTOPERATIVE PAIN AND OPIOID REQUIREMENT FOLLOWING SURGERIES IN THE ANTERIOR PART OF THE NECK
}

\author{
Nikhil M. P1, Prashant Mallya ${ }^{2}$
}

${ }_{1}^{1}$ Associate Professor, Department of Anaesthesiology, K. S. Hegde Hospital.

${ }^{2}$ Associate Professor, Department of Anaesthesiology, K. V. G. Medical College.

\begin{tabular}{l}
\hline ABSTRACT \\
\hline BACKGROUND \\
Acute postoperative pain has resulted in physiological and psychological disturbances. In spite of the spectacular advances in \\
pain relief during surgery, relief of pain in the postoperative period still remains a problem. Here, we decided to study the effect of \\
pre-emptive oral gabapentin on postoperative pain and opioid requirement.
\end{tabular}

AIMS

To evaluate the effect of pre-emptive gabapentin on postoperative pain and opioid requirement following surgeries in the neck area. To observe for the change in heart rate and blood pressure following surgery for 24 hrs. post-operatively. To observe for the incidence of nausea and vomiting.

\section{MATERIALS AND METHODS}

The patients selected for elective surgical procedures were randomly allocated into two groups, a control Group C and a gabapentin Group G of 30 members each. Patients in Group C received B-complex capsule orally as placebo 2 hours prior to surgery and those in Group B received gabapentin $300 \mathrm{mg}$ orally 2 hours before surgery. After surgery, pain scores were assessed by a blinded person using visual analogue scale hourly for first 24 hours. Pethidine $1 \mathrm{mg} / \mathrm{kg}$ slow IV was given if pain score was 4 or more. Also adverse effects in the form of nausea and vomiting were documented. Statistical analysis of all the quantitative data was done by using the 'Student's unpaired t-test' (e.g.: Mean Age, Vas Scores, Heart Rate, Systolic Blood Pressure, Diastolic Blood Pressure). Statistical analysis of all the qualitative data was done by using Chi ( $\left.\chi^{2}\right)$ square test (e.g.: Gender, Nausea, Vomiting). Inter-group comparison of pethidine requirement was done using Mann-Whitney ' $\mathrm{u}$ ' test (Z).

\section{RESULTS}

Patients in the gabapentin group had significantly lower VAS scores at all-time intervals of 0-6, 7-12, 13-18, 19-24 hours than those in the control group and it was statistically significant. Total pethidine requirement after surgery in the first 24 ho urs in the gabapentin group was $(47 \pm 23.51)$ when compared to control group $(163.17 \pm 39.72)(p=0.001)$, which was statistically significant. Patients in gabapentin group had better haemodynamics.

\section{CONCLUSION}

Gabapentin $300 \mathrm{mg}$ given orally 2 hours prior to surgeries in the neck effectively reduced postoperative pain and pethidine requirement in the first 24 hours postoperatively with better haemodynamics. Thus $300 \mathrm{mg}$ of gabapentin can be safely used preemptively in patients undergoing elective surgeries, which significantly reduce opioid requirement.

\section{KEYWORDS}

Post-operative Pain, Pre-Emptive Analgesia, Gabapentin, Head and Neck Surgeries.

HOW TO CITE THIS ARTICLE: Nikhil MP, Mallya P. The effect of preemptive gabapentin on postoperative pain and opioid requirement following surgeries in the anterior part of the neck. J. Evolution Med. Dent. Sci. 2016;5(36):2142-2146, DOI: $10.14260 /$ jemds/2016/500

\section{INTRODUCTION}

Although physician have sought to alleviate pain for centuries, the history of pain research and modern pain treatment begins in 1800 s. The enigma of pain, which Albert Schweitzer called "The most terrible of all the lords of mankind," has yielded slowly to determined investigators and clinicians. ${ }^{1}$ Pain is mysterious in many ways. It is experienced by almost all of us at one time or another in our lives and some of us experience it almost continuously. ${ }^{2}$

Financial or Other, Competing Interest: None.

Submission 21-03-2016, Peer Review 14-04-2016,

Acceptance 21-04-2016, Published 05-05-2016.

Corresponding Author:

Dr. Nikhil M. P,

Associate Professor,

Department of Anaesthesiology,

K. S. Hegde Hospital, Deralakatte,

Mangalore-575018.

E-mail: mpcas79@gmail.com

DOI: $10.14260 /$ jemds $/ 2016 / 500$
The international association for the study of pain defines it as "An unpleasant sensory and emotional experience associated with actual or potential tissue damage or described in terms of such damage."3 Unrelieved acute pain results in potentially life-threatening adverse physiological effects and may also cause psychological disturbances. Postoperative pain is something in particular, which at times we treat or at times have to endure. In modern postoperative care this means effective relief from pain, suffering, anxiety and sleeplessness. Thus, the outcome of the postoperative recovery may be greatly influenced by effective pain management.

The term "Pre-emptive analgesia" implies that an analgesic treatment given before nociceptive stimuli reach the central nervous system could prevent or reduce the subsequent pain. ${ }^{4}$ Anaesthesiologist's main role is to enable the patient to undergo surgical and other painful procedures without pain or anxiety. 
In spite of the spectacular advances in pain relief during surgery, relief of pain in the postoperative period still remains a problem. Gabapentin is reported to possess antihyperalgesic and antiallodynia properties. Recent studies have showed that pre-emptive gabapentin reduce postoperative pain and opioid requirement following thyroid surgeries, lumbar discoidectomy.5,6

\section{AIMS AND OBJECTIVES}

- To evaluate the effect of pre-emptive gabapentin on postoperative pain and opioid requirement following surgeries in the anterior part of the neck.

- To observe for the change in heart rate and blood pressure following surgery for $24 \mathrm{hrs}$. post-operatively.

- To observe for the incidence of nausea and vomiting.

\section{MATERIALS AND METHODS}

After Institutional Ethics Committee approval, this study was done on 60 ASA Grade I and II patients, aged between 18-60 years who had to undergo elective surgical procedures in the anterior part of the neck in a district hospital affiliated to our institute. After informed written consent, pre-anaesthetic evaluation consisting of detailed history and physical examination was done. Patients with impaired renal and hepatic functions, uncontrolled diabetes mellitus, pregnancy, alcohol abuse, analgesics intake within 24 hours prior to surgery were excluded from the study. Those patients in whom surgical time extended beyond 3 hours were also excluded. The patients selected for elective surgical procedures were randomly allocated into two groups, a control Group C and a gabapentin Group G of 30 members each. Patients in Group C received B-complex capsule orally as placebo 2 hours prior to surgery and those in Group B received gabapentin $300 \mathrm{mg}$ orally 2 hours before surgery.

Each one of the patients were made familiar with visual analogue scale scores in their own language on the previous day of surgery. Adequate nil per oral status were obtained. All patients were premedicated with diazepam $5 \mathrm{mg}$ on the night before surgery, tablet ranitidine $150 \mathrm{mg}$ on the previous night and 2 hours before surgery. In the operating room standard anaesthesia monitors were applied and IV access secured. After adequately pre-oxygenating with 100\% oxygen, pethidine $1 \mathrm{mg} / \mathrm{kg}$ IV was used for analgesia. We chose pethidine as it was available opioid in our hospital. Anaesthesia was induced with propofol $2 \mathrm{mg} / \mathrm{kg}$ and neuromuscular blockade with vecuronium $0.1 \mathrm{mg} / \mathrm{kg}$. Intubation was performed with appropriate size cuffed endotracheal tube. Anaesthesia was maintained with $66 \%$ nitrous oxide in oxygen and isoflurane of $1 \mathrm{MAC}$.

No other analgesics were administered during the surgery. Fluids and blood losses were replaced according to Holliday and Segar formula. At the end of surgery residual neuromuscular blockade was reversed with neostigmine 0.05 $\mathrm{mg} / \mathrm{kg}$ and glycopyrrolate $0.01 \mathrm{mg} / \mathrm{kg}$. Patients were transferred to post-anaesthesia care unit after extubation. A senior resident who was not a part of anaesthesia team recorded pain scores at rest on a visual analogue scale at 1 hour and then hourly till 24 hours post-operatively.

All patients received pethidine $1 \mathrm{mg} / \mathrm{kg}$ slow IV when pain scores were four or more. Average pain scores and total pethidine requirement in first 24 hours were recorded. Heart rate, systolic and diastolic blood pressure hourly for 24 hours were also recorded.
Also adverse effects in the form of nausea and vomiting were documented. All observations were documented in the proforma, which was provided in each case to the blinded observer.

\section{OBSERVATION AND RESULTS}

There were 30 patients in each group. All the observations were recorded in the proforma. Statistical analysis of all the quantitative data was done by using the 'Student's unpaired ttest' (e.g. Mean Age, Vas Scores, Heart Rate, Systolic Blood Pressure, Diastolic Blood Pressure). Statistical analysis of all the qualitative data was done by using Chi $\left(\chi^{2}\right)$ square test (e.g. Gender, Nausea, Vomiting). Inter-group comparison of pethidine requirement was done using Mann-Whitney ' $u$ ' test (Z). Data obtained was presented as mean 2 standard deviation. ' $P$ ' value was calculated and interpreted as:

$\mathrm{p}$ value $<0.05$ - Statistically 'Significant,' SIG.

$\mathrm{p}$ value $<0.01$ - Statistically 'Highly significant' HS

$\mathrm{p}$ value $<0.001$ - Statistically 'Very Highly Significant' VHS

$\mathrm{p}$ value $>0.05$ - Statistically 'Not Significant' NS.

\section{Demographic Data}

\begin{tabular}{|c|c|c|c|c|}
\hline Group & N & Mean & $\begin{array}{c}\text { Std. } \\
\text { Deviation }\end{array}$ & T \\
\hline Control (C) & 30 & 40.57 & 11.996 & $\mathrm{p}=1.335 \mathrm{~ns}$ \\
\hline Study (G) & 30 & 36.57 & 11.190 & $\mathrm{p}=0.187 \mathrm{~ns}$ \\
\hline \multicolumn{5}{|c|}{ Table 1: (Intergroup Comparison of Statistical } \\
Significance with Respect to Age) \\
\hline
\end{tabular}

\begin{tabular}{|c|c|c|c|c|c|}
\hline & \multicolumn{2}{|c|}{ Group } & \multirow[b]{2}{*}{ Total } \\
\hline & & & $\begin{array}{l}\text { Control } \\
\text { (C) }\end{array}$ & $\begin{array}{c}\text { Gabapentin } \\
\text { (G) }\end{array}$ & \\
\hline \multirow[t]{2}{*}{ Sex } & M & $\begin{array}{c}\text { Count } \\
\%\end{array}$ & $\begin{array}{c}21 \\
72.4 \% \\
\end{array}$ & $\begin{array}{c}15 \\
50.0 \% \\
\end{array}$ & $\begin{array}{c}36 \\
61.0 \% \\
\end{array}$ \\
\hline & $\mathrm{F}$ & $\begin{array}{c}\text { Count } \\
\%\end{array}$ & $\begin{array}{c}8 \\
27.6 \% \\
\end{array}$ & $\begin{array}{c}15 \\
50.0 \% \\
\end{array}$ & $\begin{array}{c}23 \\
39.0 \% \\
\end{array}$ \\
\hline Total & & $\begin{array}{c}\text { Count } \\
\%\end{array}$ & $\begin{array}{c}29 \\
100.0 \%\end{array}$ & $\begin{array}{c}30 \\
100.0 \%\end{array}$ & $\begin{array}{c}59 \\
100.0 \%\end{array}$ \\
\hline
\end{tabular}

a. $\mathrm{X} 2=3.114 \mathrm{p}=0.074 \mathrm{~ns}$

Intergroup Comparison of Visual Analogue Scale Pain Scores (VAS) Postoperatively for 24 hours following surgery at different time intervals.

\begin{tabular}{|c|c|c|c|c|c|}
\hline $\begin{array}{c}\text { Time } \\
\text { (hr.) }\end{array}$ & Group & N & Mean & $\begin{array}{c}\text { Std. } \\
\text { Deviation }\end{array}$ & $\mathbf{T}$ \\
\hline $0-6$ & Control & 30 & 3.1663 & .34802 & 13.80800 \\
\hline & Gabapentin & 30 & 1.6907 & .47064 & $\begin{array}{c}\mathrm{P}=0.01 \\
\text { vhs }\end{array}$ \\
\hline $7-12$ & Control & 30 & 2.3587 & .57993 & 2.09400 \\
\hline & Gabapentin & 30 & 2.0580 & .53144 & $\begin{array}{c}\mathrm{P}=0.041 \\
\text { sig }\end{array}$ \\
\hline $13-18$ & Control & 30 & 1.8517 & .76448 & 2.40300 \\
\hline & Gabapentin & 30 & 1.4580 & .46975 & $\begin{array}{c}\mathrm{P}=0.019 \\
\text { sig }\end{array}$ \\
\hline $19-24$ & Control & 30 & 1.3960 & .76129 & 2.51100 \\
\hline & Gabapentin & 30 & 1.0003 & .40684 & $\begin{array}{c}\mathrm{P}=0.015 \\
\text { sig }\end{array}$ \\
\hline \multicolumn{5}{|c}{ Table 3 } \\
\hline
\end{tabular}




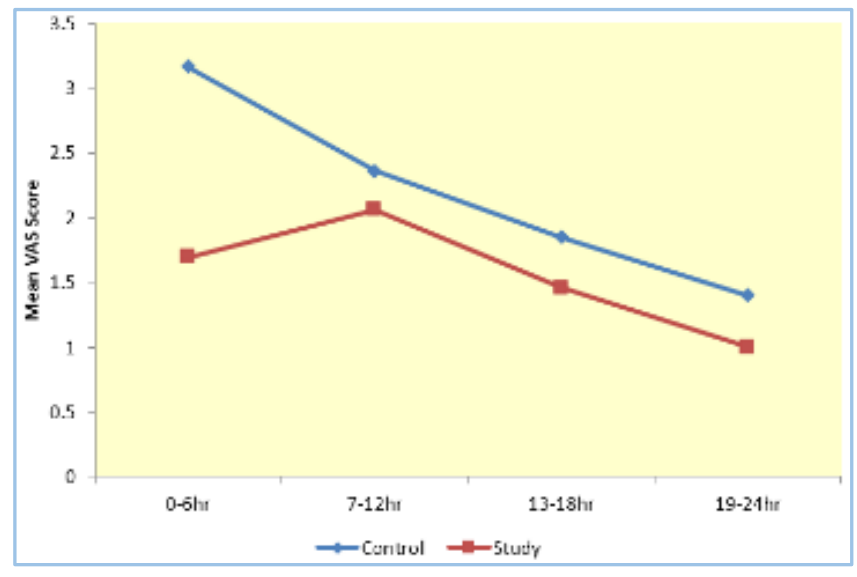

Fig. 1: Intergroup Comparison of Pethidine Requirement Post-operatively 24 hours Following Surgery at different Time Intervals

\begin{tabular}{|c|c|c|c|c|}
\hline Group & N & Mean & Std. Deviation & T \\
\hline Control & 30 & 163.1667 & 39.72933 & 6.67600 \\
\hline Gabapentin & 30 & 47.0000 & 23.51082 & $\begin{array}{c}\mathrm{P}=0.001 \\
\text { vhs }\end{array}$ \\
\hline \multicolumn{5}{|c|}{ Table 4 } \\
\hline
\end{tabular}

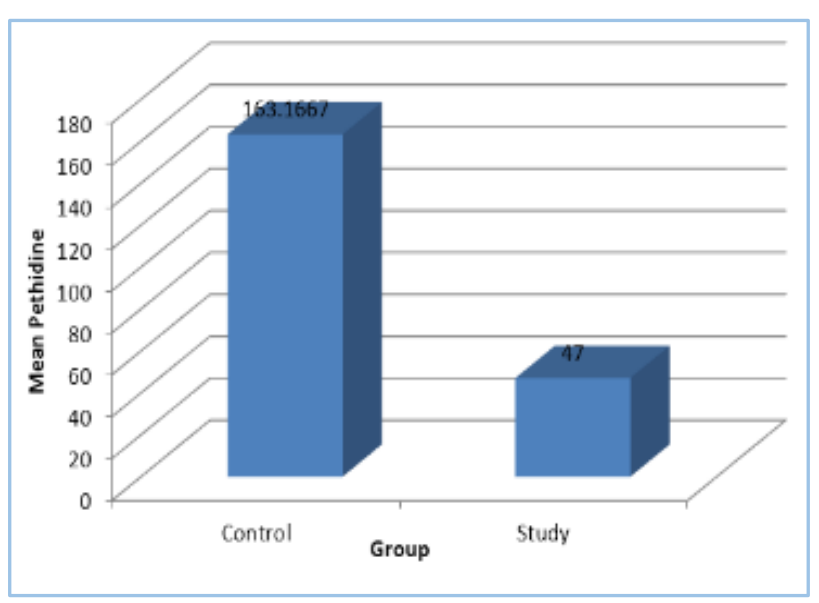

Fig. 2: Intergroup Comparison of Heart Rate Postoperatively for 24 hours following Surgery at different Time Intervals

\begin{tabular}{|c|c|c|c|c|c|}
\hline $\begin{array}{c}\text { Time } \\
\text { (hr.) }\end{array}$ & Group & N & Mean & $\begin{array}{c}\text { Std. } \\
\text { Deviation }\end{array}$ & T \\
\hline $0-6$ & Control & 30 & 90.200 & 4.965 & 6.74200 \\
\hline & Gabapentin & 30 & 79.733 & 6.903 & $\begin{array}{c}\mathrm{P}=0.001 \\
\text { vhs }\end{array}$ \\
\hline $7-12$ & Control & 30 & 88.467 & 6.532 & 8.41800 \\
\hline & Gabapentin & 30 & 75.867 & 4.953 & $\begin{array}{c}\mathrm{P}=0.001 \\
\text { vhs }\end{array}$ \\
\hline $13-18$ & Control & 30 & 84.533 & 5.482 & 9.76800 \\
\hline & Gabapentin & 30 & 71.533 & 4.805 & $\begin{array}{c}\mathrm{P}=0.001 \\
\text { vhs }\end{array}$ \\
\hline $19-24$ & Control & 30 & 79.933 & 8.196 & 6.26400 \\
\hline & Gabapentin & 30 & 69.500 & 4.006 & $\begin{array}{c}\mathrm{P}=0.001 \\
\text { vhs }\end{array}$ \\
\hline \multicolumn{5}{|c}{ Table 5 } \\
\hline
\end{tabular}

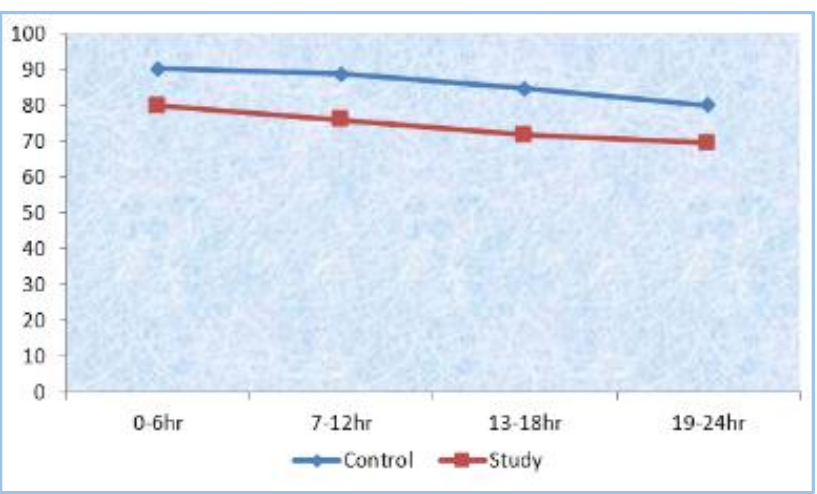

Fig. 3: Intergroup Comparison of Systolic Blood Pressure Post-operatively for 24 hours following Surgery at different Time Intervals

\begin{tabular}{|c|c|c|c|c|c|}
\hline $\begin{array}{c}\text { Time } \\
\text { (hr.) }\end{array}$ & Group & N & Mean & $\begin{array}{c}\text { Std. } \\
\text { Deviation }\end{array}$ & T \\
\hline $0-6$ & Control & 30 & 139.8667 & 9.03531 & 6.74200 \\
\hline & Gabapentin & 30 & 131.2667 & 5.18575 & $\begin{array}{c}\mathrm{P}=0.001 \\
\text { vhs }\end{array}$ \\
\hline $7-12$ & Control & 30 & 137.6667 & 8.77431 & 8.41800 \\
\hline & Gabapentin & 30 & 129.0000 & 3.14039 & $\begin{array}{c}\mathrm{P}=0.001 \\
\text { vhs }\end{array}$ \\
\hline $13-18$ & Control & 30 & 134.1333 & 8.51665 & 9.76800 \\
\hline & Gabapentin & 30 & 125.3333 & 4.43601 & $\begin{array}{c}\mathrm{P}=0.001 \\
\text { vhs }\end{array}$ \\
\hline $19-24$ & Control & 30 & 131.8000 & 8.37649 & 6.26400 \\
\hline & Gabapentin & 30 & 124.2000 & 3.87209 & $\begin{array}{c}\mathrm{P}=0.001 \\
\text { vhs }\end{array}$ \\
\hline \multicolumn{5}{|c|}{ Table 6 } \\
\hline
\end{tabular}

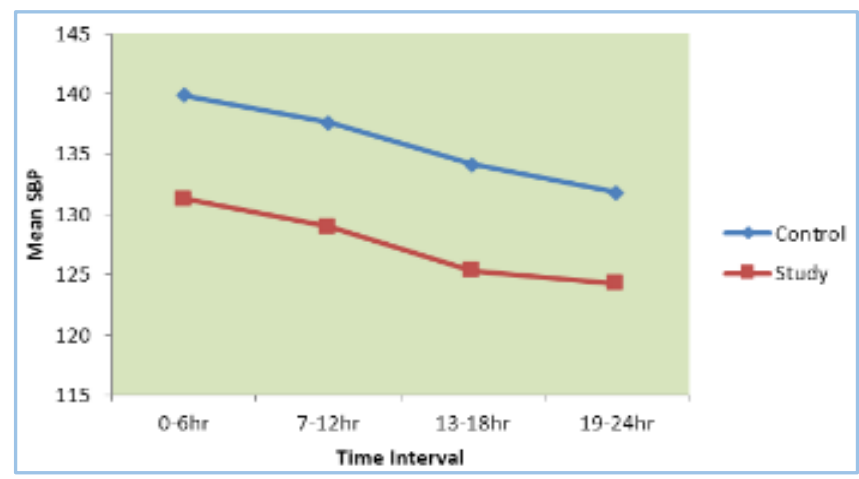

Fig. 4: Intergroup Comparison of Diastolic Blood Pressure Post-operatively for 24 hours following Surgery at different Time Intervals

\begin{tabular}{|c|c|c|c|c|c|}
\hline $\begin{array}{c}\text { Time } \\
\text { (hr.) }\end{array}$ & Group & N & Mean & $\begin{array}{c}\text { Std. } \\
\text { Deviation }\end{array}$ & T \\
\hline $0-6$ & Control & 30 & 82.4667 & 4.28899 & 2.92300 \\
\hline & Gabapentin & 30 & 80.0667 & 1.33735 & $\begin{array}{c}\mathrm{P}=0.005 \\
\text { hs }\end{array}$ \\
\hline $7-12$ & Control & 30 & 82.2000 & 5.12869 & 2.41500 \\
\hline & Gabapentin & 30 & 79.9333 & .36515 & $\begin{array}{c}\mathrm{P}=0.019 \\
\text { hs }\end{array}$ \\
\hline $13-18$ & Control & 30 & 81.8667 & 4.75419 & 2.60000 \\
\hline & Gabapentin & 30 & 79.5333 & 1.25212 & $\begin{array}{c}\mathrm{P}=0.012 \\
\text { hs }\end{array}$ \\
\hline $1-24$ & Control & 30 & 81.0667 & 5.19239 & 2.35800 \\
\hline & Gabapentin & 30 & 78.4000 & 3.37945 & $\begin{array}{c}\mathrm{P}=0.022 \\
\text { hs }\end{array}$ \\
\hline \multicolumn{5}{|c}{ Table 6 } \\
\hline
\end{tabular}




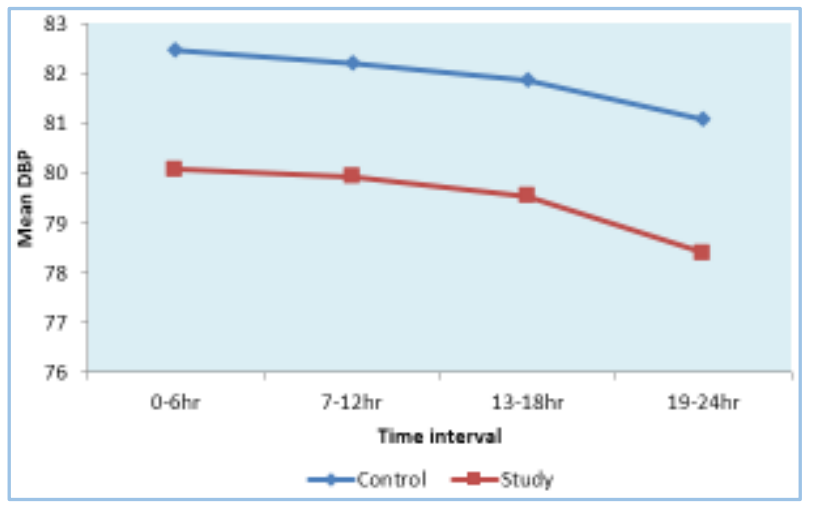

Fig. 5: Intergroup Comparison of Nausea 24 hours Postoperatively

\begin{tabular}{|c|c|c|}
\hline Nausea & Control & Gabapentin \\
\hline Yes & $5(16.71 \%)$ & $4(13.3 \%)$ \\
\hline No & $25(83.3 \%)$ & $26(86.7 \%)$ \\
\hline \multicolumn{3}{|c|}{30} \\
\hline
\end{tabular}

$\chi^{2}=0.131, p=0.718 \mathrm{NS}$

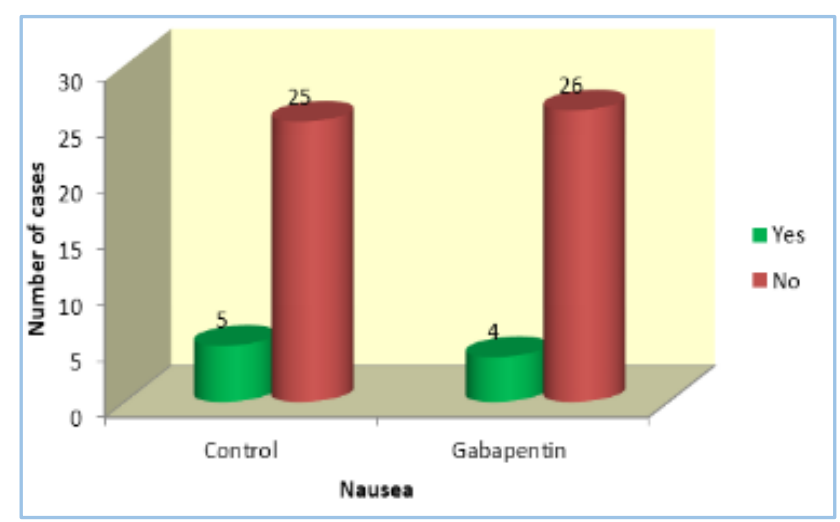

Fig. 6: Intergroup Comparison of Vomiting 24 hours Postoperatively

\begin{tabular}{|c|c|c|}
\hline Vomiting & Control & Gabapentin \\
\hline Yes & $3(10 \%)$ & $2(6.67 \%)$ \\
\hline No & $27(90 \%)$ & $28(93.33 \%)$ \\
\hline \multicolumn{3}{|c|}{30} \\
\hline \\
\hline \multicolumn{3}{|c|}{ Table 8} \\
\hline
\end{tabular}

$\chi^{2}=0.218, p=0.64 \mathrm{NS}$

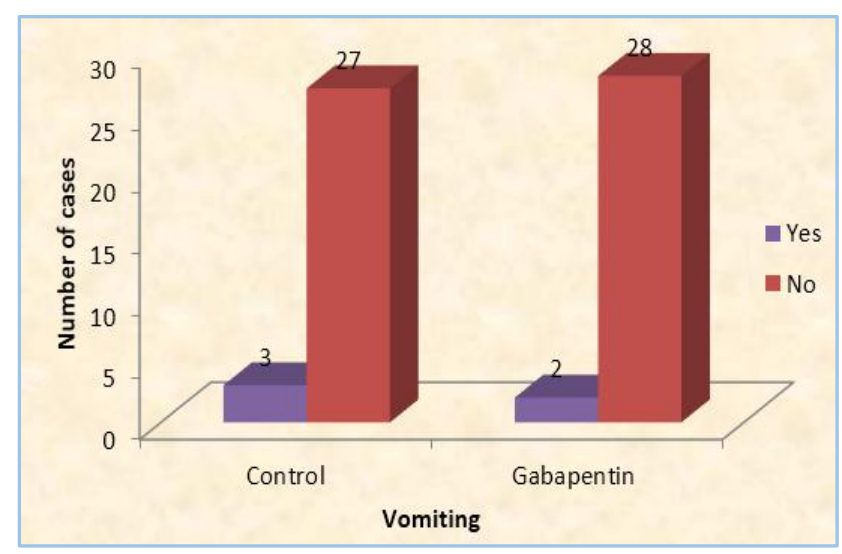

Fig. 7

\section{DISCUSSION}

Patient with significant postoperative pain should be treated adequately. In addition to having insomnia, restlessness, anxiety, nausea, vomiting, these patients can have lifethreatening respiratory and cardiovascular complications in susceptible individuals. The physiological consequences of unrelieved pain are many and may contribute to postsurgical morbidity. In this study, the efficacy of $300 \mathrm{mg}$ of gabapentin administered orally two hours prior to elective surgery in diminishing postoperative pain and pethidine requirement were evaluated.

Our study showed that gabapentin $300 \mathrm{mg}$ given per oral two hours prior to elective surgery effectively reduced post-operative pain and pethidine requirement in the first 24 hours postoperatively following surgeries in the head and neck region. Also heart rate, systolic and diastolic blood pressure were lower in the gabapentin group when compared to control group. There was statistical significance when compared to nausea and vomiting between control and gabapentin group.

Pandey CK et al showed that gabapentin $300 \mathrm{mg}$ given two hours prior to lumbar discoidectomy effectively reduced postoperative pain and fentanyl requirement in the first 24 hours following surgery. ${ }^{6}$ We used pethidine based on availability of opioid in the district hospital. Possible explanation for higher incidence of nausea and vomiting in the study conducted by Pandey $\mathrm{CK}$ et $\mathrm{al}^{7}$ could be use of laparoscopic technique in their patients. Pandey CK et al has shown that gabapentin $600 \mathrm{mg}$ had lower VAS scores than when patients received $300 \mathrm{mg} .^{7}$ The rationale behind using gabapentin $300 \mathrm{mg}$ was that the bio availability of a single $300 \mathrm{mg}$ oral dose of gabapentin is $60 \%$ and decreases with increasing dose. Oral administration of gabapentin approximately two hours prior to surgery appears rational in order to attain maximum plasma concentration at the time of surgical stimuli.

Dirks J et al demonstrated analgesic efficacy of gabapentin used pre-emptively in patients who underwent mastectomy. ${ }^{8}$ This study showed that about $50 \%$ reduction in morphine consumption in gabapentin group, which is almost similar to our study which shows nearly $65 \%$ reduction in pethidine consumption in pethidine group. Woolf CS et al has proved that peripheral tissue injury such as that caused by surgery provokes two kinds of modification in responsiveness of nervous system, peripheral sensitization which causes reduction in the threshold of nociceptor afferent peripheral terminals and central sensitization which causes an activity dependent increase in the excitability of spinal neurons.

Together, these changes contribute to a hypersensitivity state, which manifests an increase in the response to noxious stimuli both at the site and uninjured tissues. The rationale for pre-emptive analgesia is to prevent this hypersensitization. ${ }^{9}$ Tippana EM et al conducted a randomized, controlled trial examining analgesic efficacy of gabapentin given preoperatively and concluded that pain relief was better in gabapentin group and opioid requirement was reduced in gabapentin group. ${ }^{10}$ Montazeri $\mathrm{K}$ et al conducted a randomized controlled study to evaluate whether pre-emptive use of gabapentin could reduce postoperative pain and opioid consumption after lower extremity orthopaedic surgery. 
They concluded that gabapentin group had significantly lower VAS scores at all-time intervals and opioid consumption was lower in gabapentin group compared to placebo. Similar results were observed in our study, where VAS scores and opioid requirements were significantly lower in the gabapentin group compared to placebo group. ${ }^{11}$ Mikkelsen $\mathrm{S}$ et al studied the efficacy of gabapentin on postoperative pain following tonsillectomy in adults and showed that gabapentin effectively reduced opioid requirements and pain scores first 24 hours postoperatively with doses of $1200 \mathrm{mg}$ pre-emptive. Significant incidence of side effects in the form of dizziness and gait disturbances were observed, which were not seen in our study. We may be able to justify probably due to lower doses of gabapentin used. 12

Mujadi HA et al conducted a study using gabapentin $1200 \mathrm{mg} 2$ hours prior to induction of anaesthesia to patients undergoing elective thyroidectomy. They concluded that preoperative gabapentin decreased pain scores and postoperative morphine consumption in patients following thyroid surgery. ${ }^{5}$ This study is comparable to our study in terms of surgical procedure. VAS scores, opioid requirement and incidence of nausea and vomiting were lower in this study. Thus, the above study authenticates our study.

Pandey CK et al evaluated the optimal pre-emptive dose of gabapentin for postoperative pain relief after single level lumbar diskectomy and its effect on fentanyl consumption. They concluded that patients who received gabapentin 300 mg had significantly lower VAS scores at all-time points and decreased fentanyl consumption. Patients who received 600, 900 and $1200 \mathrm{mg}$ had lower VAS scores than those who received gabapentin $300 \mathrm{mg}$. Increasing the dose from 600 to $1200 \mathrm{mg}$ did not decrease the VAS scores. They concluded that gabapentin $600 \mathrm{mg}$ was the optimal dose.13 Thus, our study is comparable to the above mentioned study in that we observed lower VAS scores in the gabapentin group, which was statistically significant. In this study Heart rate, Systolic and Diastolic Blood Pressure were lower in gabapentin group when compared to control groups.

\section{LIMITATION}

Pain has no standard definition (Though IASP Taxonomy Committee Definition is Accepted), and as it is a subjective phenomenon associated with wide variability of responses among different individuals hence difficult to standardize. In other words, what may be intolerable pain to one person may be tolerable pain to another; under these circumstances it is difficult to assess and grade pain in a standard manner leading to lot of unwanted bias in the study.

Despite the consensus that post-operative pain treatment should allow patients to move around more easily, the study assessed pain relief while the patient was resting. This is rather unfortunate, as differences in efficacy between different treatment modalities may appear only when pain is assessed during function compared to rest. This could not be done due to time and personal limitation.

\section{List of Type of Surgeries}

\begin{tabular}{|c|c|}
\hline Type & Number \\
\hline Thyroid swellings & 46 \\
\hline Thyroglossal cyst & 04 \\
\hline Branchial cyst & 02 \\
\hline Lymph node excision & 08 \\
\hline
\end{tabular}

\section{CONCLUSION}

Gabapentin $300 \mathrm{mg}$ given orally 2 hours prior to surgeries in the neck effectively reduced postoperative pain and pethidine requirement in the first 24 hours postoperatively. Gabapentin group had lower heart rate, lower systolic and diastolic blood pressure in the first 24 hours postoperatively when compared to control group. No statistical difference in nausea and vomiting was observed between the two groups. Thus, $300 \mathrm{mg}$ of gabapentin can be safely used pre-emptively in patients undergoing elective surgeries which significantly reduce opioid requirement.

\section{REFERENCES}

1. Liebeskind JC. Relief of pain and suffering. Louise M Darling biomedicallibrary. UCLA, available from: www.library.ucla.edu/biomed/his/pain exhibit.

2. Rey R, Wallace LE, Cadden JA, et al. The history of pain. American historical review 1997;102(2):421-2.

3. Merskey H, Bugduk N. Classification of chronic pain. Descriptions of chronic pain syndromes and definitions of pain terms. Seattle, WA: IASP press. 1994; $2^{\text {nd }}$ ed.

4. Gottin L, Finco G, Polati E, et al. The pre-emptive analgesia in the treatment of postoperative pain. Chir Ital 1995;47(6):12-9.

5. Mujadi HA, Rahman A, Katzarov MG, et al. Pre-emptive gabapentin reduces postoperative pain and opioid demand following thyroid surgery. Can J Anaesth 2006;53(3):268-73.

6. Pandey CK, Sahay SS, Gupta D, et al. Pre-emptive gabapentin decreases postoperative pain after lumbar discoidectomy. Can J Anaesth 2004;51(10):986-9.

7. Pandey CK, Priye S, Ambesh SP, et al. Prophylactic gabapentin for prevention of postoperative nausea andvomiting in patients undergoing laparoscopic cholecystectomy: a randomized, double blind, placebocontrolled study. JPGM 2006;52(2):97-100.

8. Dirks J, Fredensborg BB, Christensen D, et al. A randomized study of the effects of single dose gabapentin versus placebo on postoperative pain and morphine consumption after mastectomy. Anaesthesiology 2002;97(3):560-4.

9. Woolf CJ, Chong MS. Pre-emptive analgesia treating postoperative pain by preventing the establishment of central sensitization. Anaesthesia analgesia 1993;77(2):362-79.

10. Tippana EM, Hamunen K, Kontinen VK, et al. Do surgical patients benefit from perioperative gabapentin/ pregabalin? A systematic review of efficacy and safety. Anaesth Analg 2007;104(6):1545-56.

11. Montazeri K, Kashefi P, Honarmand A. Pre-emptive gabapentin significantly reduces postoperative pain and morphine demand following lower extremity orthopaedic surgery. Singapore Med J 2007;48(8):748-51.

12. Mikkelson S, Hilsted KL, Anderson PJ, et al. The effect of gabapentin on postoperative pain following tonsillectomy in adults. Acta anaesthesiologica Scandinavica 2006;50(7):809-15.

13. Pandey CK, Navkar DV, Giri PJ, et al. Evaluation of the optimal pre-emptive dose of gabapentin for postoperative pain relief after lumbar diskectomy: a randomized, double-blind, placebo-controlled study. J neurosurg Anaesthesiol 2005;17(2):65-8. 